\title{
Gender and Ethnic Disparities in Incidence and Survival of Squamous Cell Carcinoma of the Oral Tongue, Base of Tongue, and Tonsils: A Surveillance, Epidemiology and End Results Program-Based Analysis
}

\author{
Nabil F. Saba ${ }^{a}$ Michael Goodman ${ }^{b}$ Kevin Ward $^{b}$ Chris Flowers $^{a}$ \\ Suresh Ramalingam ${ }^{a}$ Taofeek Owonikoko ${ }^{a}$ Amy Chen ${ }^{c}$ William Grist ${ }^{c}$ \\ Trad Wadsworth $^{c}$ Jonathan J. Beitler ${ }^{d}$ Fadlo R. Khuria Dong M. Shin ${ }^{a}$ \\ ${ }^{a}$ Department of Hematology and Medical Oncology, Winship Cancer Institute, ${ }^{b}$ Rollins School of Public Health and \\ 'Department of Otolaryngology, Emory University, and d Department of Radiation Oncology, Emory University \\ School of Medicine, Atlanta, Ga., USA
}

\section{Key Words}

Human papillomavirus · Oropharyngeal cancer · Oral

tongue cancer - Gender disparities in head and neck cancer .

Ethnic disparities in head and neck cancer

\begin{abstract}
Background: Squamous cell carcinomas (SCC) of the oral tongue (OT) and of the base of the tongue and tonsils (BTT) differ with respect to etiology, treatment and prognosis. Human papillomavirus has been linked to the increased incidence of BTT, yet, the trends in incidence of BTT and OT tumors among gender and ethnic origin groups have not been well examined. We sought to examine the trend in gender-, ethnic origin- and age-specific incidence of these tumors over time. Methods: Data were obtained from the Surveillance, Epidemiology and End Results Program of the US National Cancer Institute. We examined temporal trends in sexand ethnic origin-specific incidence of SCC by calculating the annual percent changes followed by joinpoint analyses evaluating changes in trend. Results: While BTT increased in age-adjusted rates among white males with a more pro-
\end{abstract}

nounced increase observed in the mid-1990s, white females experienced a significant increase in incidence of OT tumors. Patients with advanced OT carcinoma had a significantly lower survival compared to those with advanced BTT disease; however, patients with early-stage OT tumors had a better survival compared to patients with BTT. Conclusions: While the increase in incidence of BTT tumors in white men is likely human papillomavirus driven, more studies are needed to elucidate the increasing incidence of OT tumors in white women. The differences in outcomes across ethnic origin groups are also described and discussed.

Copyright $\odot 2011$ S. Karger AG, Basel

\section{Introduction}

More than 500,000 people worldwide are diagnosed with squamous cell carcinomas (SCC) of the head and neck each year. Head and neck cancer is the fifth most common cancer worldwide and is the most common neoplasm in central Asia [1]. In the United States, SCC of the head and neck account for $3.3 \%$ of malignancies with an

\section{KARGER}

(C) 2011 S. Karger AG, Basel

Fax +4161306 1234

E-Mail karger@karger.ch

www.karger.com 
estimated 48,010 new cases and 11,260 deaths from the disease expected in 2009 alone [2].

SCC of the oral cavity and oropharynx account for close to 35,700 cases per year, and oral cavity tumors alone account for close to 10,500 cases per year [2]. SCC of the base of the tongue and tonsils (BTT) have a distinct behavioral pattern, and recently, through studies focusing on human papillomavirus (HPV) as a causative factor, appear to be having distinct etiologies. BTT SCC seem to be more closely related to HPV infection [3]. Moreover, it has become clear that HPV status is a strong and independent prognostic factor for survival among patients with oropharyngeal cancer, with a clearly improved survival for this group in comparison to nonHPV-related disease [4]. Given the recent changes in incidence of oropharyngeal carcinomas, we were interested in further exploring the trends with relation to ethnic origin and gender, thus studying additional environmental factors $[3,5]$. Also, we were interested in exploring any changes in oral tongue (OT) cancers which are typically not HPV related, as well as in analyzing changing trends in incidence and outcome for these two distinct diseases with likely different etiologies. We think this analysis could invite additional population-based studies that may shed light on possible environmental or infectious causes. Finally, we sought to evaluate these trends with respect to gender and ethnic origin variables in light of the recent evidence indicating that HPV-driven oropharyngeal cancers predominantly affect white males.

Primary tumors of the OT represent approximately half of all SCC of the oral cavity [6]. Tobacco smoking and alcohol use are the principal risk factors for developing OT SCC. In addition, oral tobacco use, radiation exposure, HPV, as well as immune deficiency have been implicated [7]. The prognosis for patients with OT cancer varies with stage and site.

It is estimated that approximately half of BTT SCC diagnosed in the Western world are HPV related [8]. Patients with HPV-related BTT carcinomas have a better therapeutic response and improved survival compared to their HPV-negative counterparts $[9,10]$.

In the United States, the incidence of head and neck SCC in African American (AA) men is approximately $50 \%$ higher than in white men [11]. It is also known that AAs tend to have a worse outcome compared to Whites. This discrepancy may be in part related to the lower proportion of HPV-positive tumors among AA patients; however, other factors may be involved and need to be examined [12].

Gender and Ethnic Disparities in Tongue and Oropharyngeal Cancers

\section{Materials and Methods}

Data were obtained from the Surveillance, Epidemiology and End Results (SEER) Program of the US National Cancer Institute [13]. All neoplasms reported to the SEER Program since 2001 have been coded using the International Classification of Diseases for Oncology, 3rd edition (ICD-O-3) [14]; those diagnosed prior to 2001 have been recoded to this classification.

Using the SEER database [15], we selected all cases with a histologic category of squamous cell neoplasms (ICD-O codes 80508089 ) and documented malignant behavior that were diagnosed between 1973 and 2006, and assigned 1 of the following 12 primary site categories: (1) dorsal surface of the tongue $(n=1,000)$; (2) border of the tongue ( $n=5,217)$; (3) ventral surface of the tongue ( $\mathrm{n}=2,198)$; (4) anterior two thirds of the tongue $(\mathrm{n}=3,310)$; (5) base of the tongue ( $\mathrm{n}=15,216)$; (6) lingual tonsil ( $\mathrm{n}=273)$; (7) tonsil, not otherwise specified $(\mathrm{n}=11,100)$; (8) tonsillar fossa $(\mathrm{n}=$ $4,303)$; (9) tonsillar pillar ( $n=2,006)$; (10) overlapping lesion of the tonsil ( $\mathrm{n}=172)$; (11) overlapping lesion of the tongue $(\mathrm{n}=1,143)$, and (12) tongue, not otherwise specified $(5,024)$. These primary cancer sites were recoded into three broad groups: OT, which included the first 4 primary site categories listed above; BTT, which included the next 6 categories, and tongue, not otherwise specified, which also included overlapping lesions.

Using data for 9 registries that provide reported cancer cases back to 1973-1975, we then examined temporal trends in incidence rates (age adjusted for the US standard population) as a function of gender and ethnic origin. Although at present SEER data are available in 9-, 13-, or 17-registry sets, the 9-registry data set is the only one that goes all the way back to 1973, and therefore, we deemed it most suitable for exploring long-term changes in incidence [16]. The definitions of SEER historic stages are as follows [17]: (1) localized cancer is cancer that is limited to the organ in which it began, without evidence of spread; (2) regional cancer is cancer that has spread beyond the original (primary) site to nearby lymph nodes or organs and tissues; (3) distant cancer is cancer that has spread from the primary site to distant organs or distant lymph nodes, and (4) unstaged cancer is cancer for which there is not enough information to indicate a stage.

The results of the trend analyses were expressed as the annual percent change (APC). The APC is calculated by fitting a least square regression line to the natural logarithm of the rates, using the calendar year as a regressor variable. The incidence data were further analyzed using joinpoint models, which are aimed to evaluate longitudinal data for a change in trend. The change in trend was tested for statistical significance using a Monte Carlo Permutation method [18]. In the presence of a significant joinpoint, two APC values were calculated, one preceding and one following the change.

Observed survival (defined as the proportion of patients surviving beyond a certain interval after the diagnosis) and relative survival (defined as the observed survival among cancer patients divided by the expected survival in the general population with the same age, sex and race characteristics) were analyzed according to different patient characteristics. Unlike frequency analyses, which included all records, survival analyses excluded 8,469 cases that represented second or later primary cancer to eliminate possible biases. Cases ascertained from autopsy records or death certificates $(\mathrm{n}=34)$ and cases known to be alive but without documented survival time $(\mathrm{n}=341)$ were also excluded. The 1 -, 3 - and 
Table 1. Characteristics of SCC cases of tongue and tonsils by cancer site group (SEER data, 17 registries, 1973-2008)

\begin{tabular}{|c|c|c|c|c|c|c|c|c|}
\hline \multirow{3}{*}{$\begin{array}{l}\text { Case } \\
\text { characteristics }\end{array}$} & \multirow{2}{*}{\multicolumn{2}{|c|}{$\begin{array}{l}\text { All cases } \\
(\mathrm{n}=51,092)\end{array}$}} & \multicolumn{6}{|c|}{ Primary site } \\
\hline & & & \multicolumn{2}{|c|}{ OT $(\mathrm{n}=11,825)$} & \multicolumn{2}{|c|}{ BTT $(\mathrm{n}=33,100)$} & \multicolumn{2}{|c|}{ tongue, $\operatorname{NOS}(n=6,167)$} \\
\hline & $\mathrm{n}$ & $\%$ & $\mathrm{n}$ & $\%$ & $\mathrm{n}$ & $\%$ & $\mathrm{n}$ & $\%$ \\
\hline \multicolumn{9}{|l|}{ Age } \\
\hline$<40$ years & 1,941 & 3.8 & 814 & 6.9 & 744 & 2.2 & 383 & 6.2 \\
\hline 40-59 years & 22,154 & 43.4 & 4,288 & 36.3 & 15,741 & 47.6 & 2,125 & 34.5 \\
\hline $60-79$ years & 23,046 & 45.1 & 5,344 & 45.2 & 14,825 & 44.8 & 2,877 & 46.7 \\
\hline $80+$ years & 3,951 & 7.7 & 1,379 & 11.7 & 1,790 & 5.4 & 782 & 12.7 \\
\hline \multicolumn{9}{|l|}{ Race } \\
\hline White & 43,416 & 85.0 & 10,066 & 85.1 & 28,111 & 84.9 & 5,239 & 85.0 \\
\hline Black & 4,960 & 9.7 & 733 & 6.2 & 3,759 & 11.4 & 468 & 7.6 \\
\hline Other $^{\mathrm{a}}$ & 2,416 & 4.7 & 940 & 7.9 & 1,094 & 3.3 & 382 & 6.2 \\
\hline Unknown & 300 & 0.6 & 86 & 0.7 & 136 & 0.4 & 78 & 1.3 \\
\hline \multicolumn{9}{|l|}{ Gender } \\
\hline Male & 36,064 & 70.6 & 6,930 & 58.6 & 25,377 & 76.7 & 3,757 & 60.9 \\
\hline Female & 15,028 & 29.4 & 4,895 & 41.4 & 7,723 & 23.3 & 2,410 & 39.1 \\
\hline \multicolumn{9}{|l|}{ Stage } \\
\hline Localized & 15,265 & 29.9 & 7,468 & 63.2 & 4,797 & 14.5 & 3,000 & 48.6 \\
\hline Regional & 26,635 & 52.1 & 3,103 & 26.2 & 21,894 & 66.1 & 1,638 & 26.6 \\
\hline Distant & 6,612 & 12.9 & 830 & 7.0 & 4,997 & 15.1 & 785 & 12.7 \\
\hline Unstaged & 2,580 & 5.0 & 424 & 3.6 & 1,412 & 4.3 & 744 & 12.1 \\
\hline \multicolumn{9}{|l|}{ Time interval } \\
\hline 1973-1981 & 5,423 & 10.6 & 1,511 & 12.8 & 3,285 & 9.9 & 627 & 10.2 \\
\hline 1982-1991 & 7,353 & 14.4 & 1,877 & 15.9 & 4,542 & 13.7 & 934 & 15.1 \\
\hline $1992^{b}-1999$ & 9,514 & 18.6 & 2,440 & 20.6 & 5,923 & 17.9 & 1,151 & 18.7 \\
\hline $2000^{\mathrm{b}}-2008$ & 28,802 & 56.4 & 5,997 & 50.7 & 19,350 & 58.5 & 3,455 & 56.0 \\
\hline
\end{tabular}

NOS $=$ Not otherwise specified.

${ }^{a}$ American Indian/Alaska Native, Asian/Pacific Islander. ${ }^{b}$ Years when new registries were added to the SEER program.

5 -year survival of patients was evaluated across patient- and disease-related characteristic and for several time periods, $1973-$ 1981, 1982-1991, 1992-1999 and 2000-2008, where the last two cutoffs correspond to the years when new SEER registries were added. The follow-up data in survival analyses extended through the end of 2008. These survival calculations were based on the actuarial life table method.

Kaplan-Meier curves were constructed to examine patient survival according to cancer site with corresponding log-rank tests for statistical significance. Cox regression models examined the association between survival and various patient- and diseaserelated characteristics with the primary focus on site and ethnic origin as independent variables of interest. Additional covariates included age, stage (dichotomized as localized vs. advanced), gender, year of diagnosis and SEER registry. The association between predictor variables and survival were expressed as adjusted hazard ratios (HRs) and reported along with the corresponding 95\% confidence intervals (CIs). Proportional hazard assumptions were tested by examining log minus log plots for each variable [19]. In addition, all models were examined for interactions and colinearity among covariates. The analyses were performed using SPSS 17.0 for Windows (LEAD Technologies, Inc., Chicago, Ill., USA) and SEER*Stat version 6.4.4 (National Cancer Institute, Bethesda, Md., USA) statistical software packages.

\section{Results}

A total of 51,092 cases were included in this study. Of those, 33,100 cancers (64.7\%) originated in the BTT and 11,825 cancers $(23.1 \%)$ in the OT (table 1 ). In 6,167 cases $(12.1 \%)$, the primary site was reported as the tongue, overlapping or not otherwise specified. A comparison of patient demographic characteristics across primary site categories revealed no striking differences by race, with roughly $85 \%$ of cases occurring among Whites. Compared to the OT group, patients diagnosed with BTT can- 


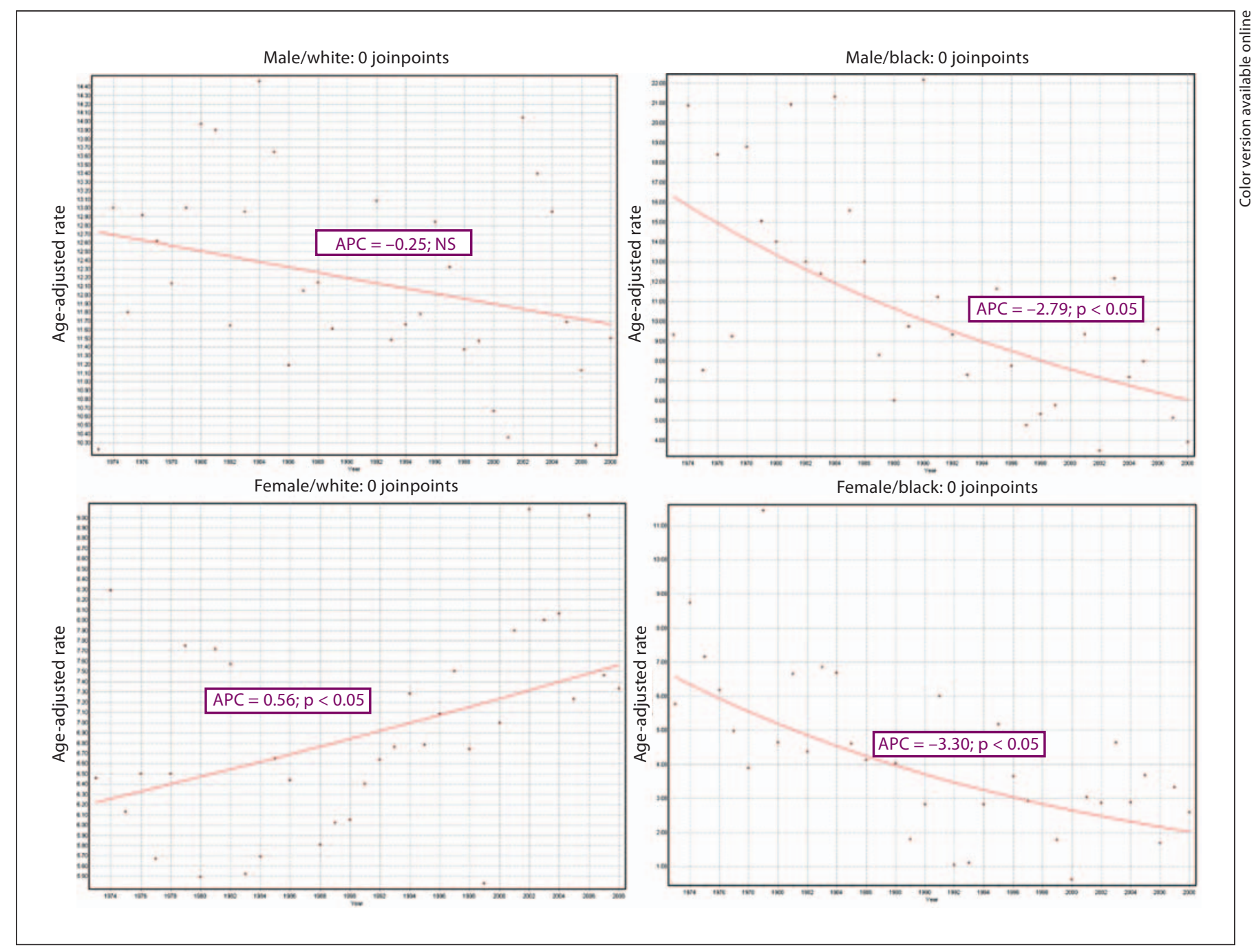

Fig. 1. Age-adjusted rates and trends of SCC of OT by sex and race using joinpoint analyses. SEER data (9 registries, 1973-2008). NS = Not significant.

cer were predominantly males (76.7 vs. $58.6 \%)$, with a lower frequency of localized disease at presentation (14.5 vs. $63.2 \%$ for BTT vs. OT, respectively) (table 1 ).

\section{Changes in Incidence}

Although changes in incidence for OT cancer between 1973 and 2006 were not significant among white males (fig. 1), there was evidence that white females experienced a significant albeit modest increase. Among AA patients, data for both males and females demonstrated significant declines in incidence. A similar examination of BTT incidence among white males demonstrated a gradual upward trend in age-adjusted rates starting in 1973 followed by a more pronounced increase starting in the mid-1990s (fig. 2) in keeping with the HPV epidemic [20]. By contrast, the incidence of BTT tumors continuously declined in both AA and white females, with an initial increase observed for AA males followed by a decline beginning in the late 1980s. A review of cancer stage data by time interval demonstrated that patients diagnosed with distant disease constituted 5\% of all OT carcinoma cases in 1973-1981 compared to 7\% in 2000-2008, whereas the proportion of unstaged disease decreased slightly from 4 to $3 \%$. The corresponding comparison of data for BTT carcinomas demonstrated a decrease from 20 to $15 \%$ and from 8 to $3 \%$ for distant and unstaged disease, respectively. 


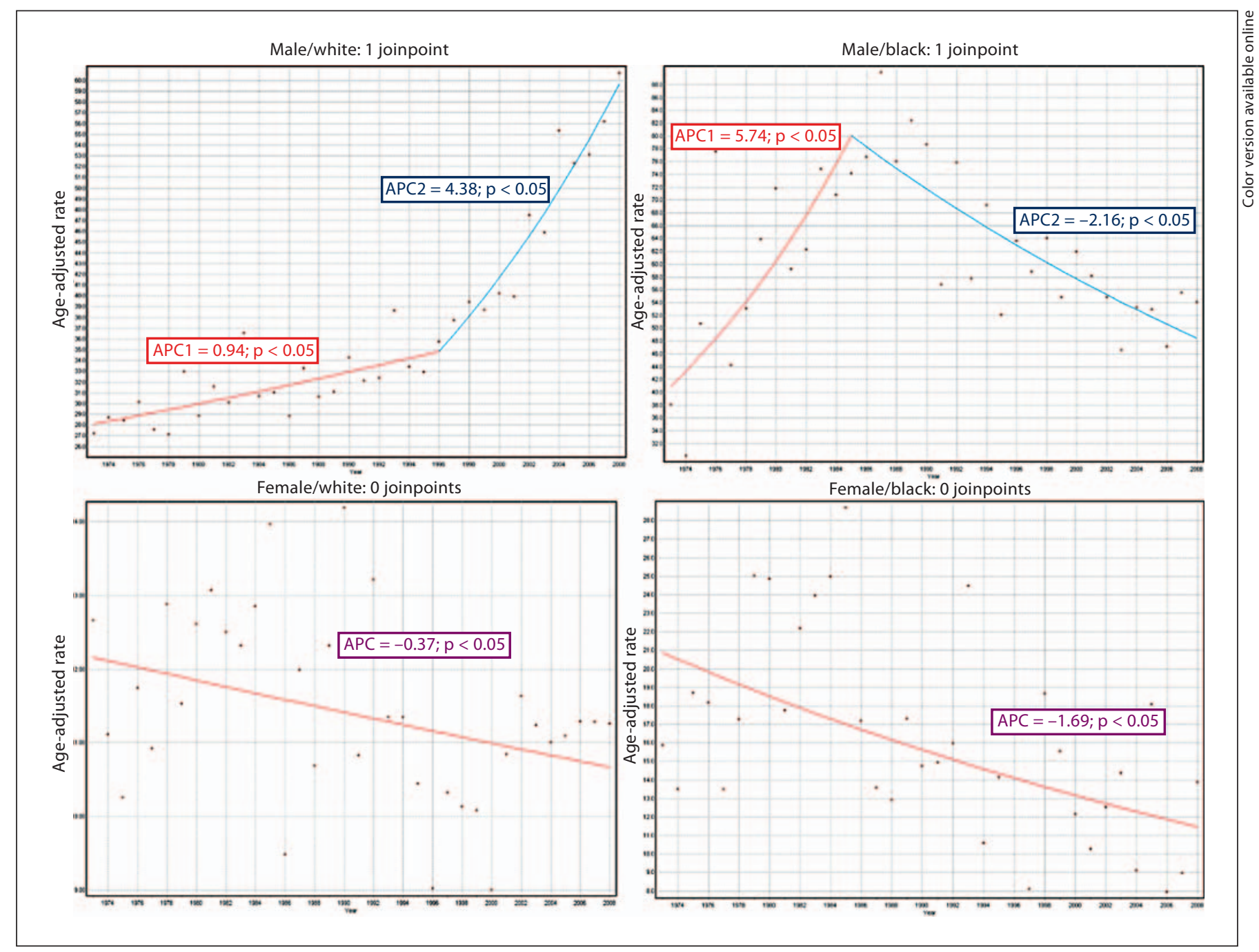

Fig. 2. Age-adjusted rates and trends of SCC of BTT by sex and race using joinpoint analyses. SEER data (9 registries, 1973-2008).

\section{Changes in Survival}

A relative overall survival of $81.7,61.7$ and $54.9 \%$ at 1 , 3 and 5 years, respectively, was noted for all patients. A decline in survival was noted with increasing age and stage. Whites had a better relative survival compared to AAs, and there was no discernable difference in relative survival between males and females. Both observed and relative survival measures showed improvements over time (table 2).

In our definition of advanced versus localized disease, we have utilized the SEER historic stage. Advanced disease included locally advanced disease as well as patients with distant metastases. In the unadjusted analyses, early-stage OT disease had a better survival compared to
BTT, with a statistically significant difference reached for Whites $(p<0.001)$ but not for AAs $(p=0.090)$. For advanced disease, survival was better for BTT cancer compared to OT, and the difference was statistically significant in both AAs and Whites with $\mathrm{p}$ values of 0.013 and $<0.001$, respectively (fig. 3 ).

In the multivariate analyses there was a strong and statistically significant $(\mathrm{p}<0.0001)$ interaction between stage and primary site, and for this reason, these results are presented separately for localized and advanced (regionally spread or distant) disease (table 3). Among patients with early-stage disease, mortality was significantly higher for BTT cancer compared to OT cancer ( $\mathrm{HR}=$ 1.28; 95\% CI 1.21-1.36). By contrast, survival was better 


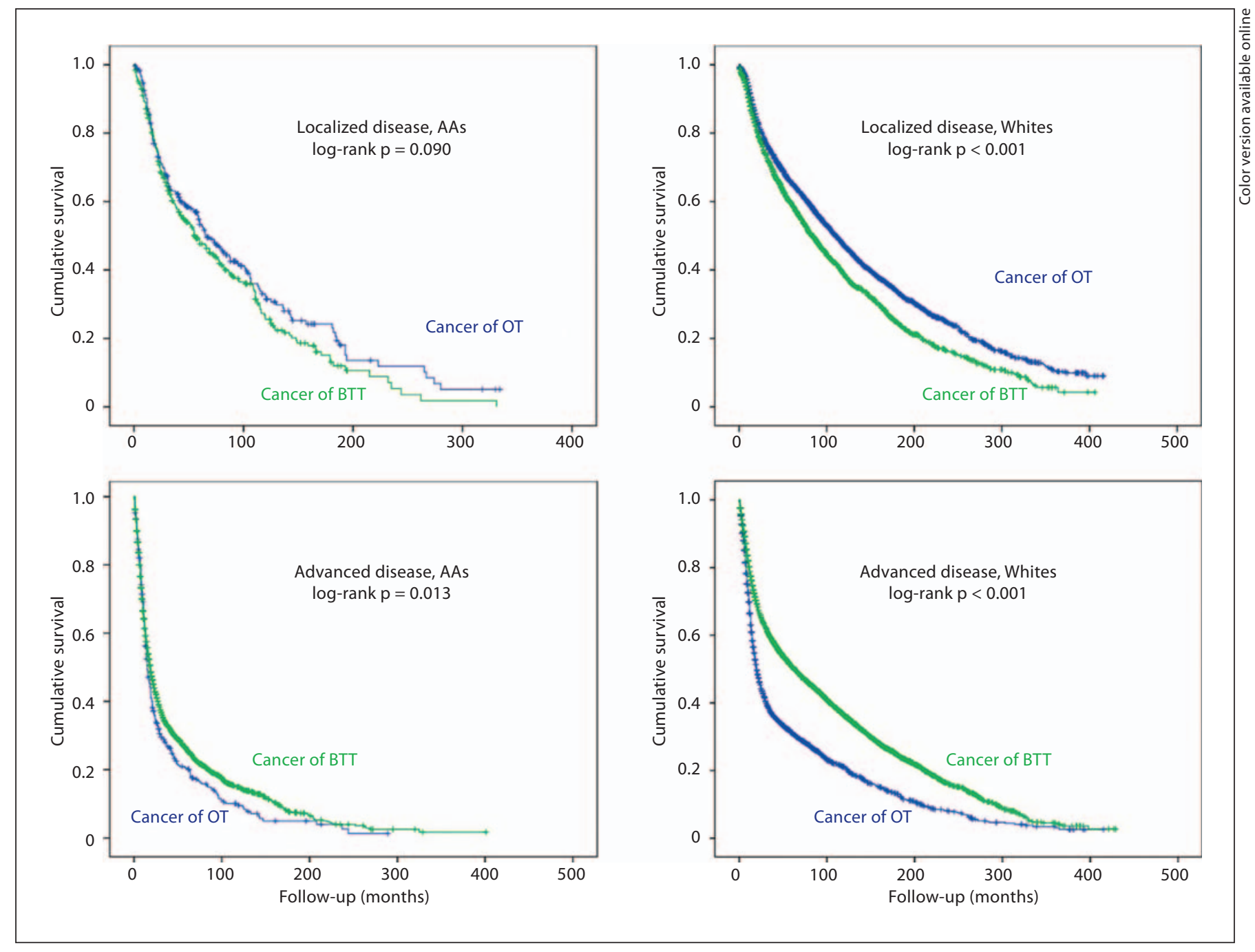

Fig. 3. Kaplan-Meier survival curves: oral cancer patients compared to patients diagnosed with cancer of BTT by stage and race. SEER data (1973-2008).

for BTT versus OT cancers when the data were limited to advanced disease ( $\mathrm{HR}=0.72 ; 95 \%$ CI $0.69-0.75)$. The multivariate analyses also demonstrated a slightly lower mortality in women compared to men. AA patients had significantly increased mortality for both localized $(\mathrm{HR}=1.59 ; 95 \% \mathrm{CI} 1.43-1.77)$ and advanced $(\mathrm{HR}=1.92$; 95\% CI 1.83-2.00) cancers regardless of the site of disease. A review of cancer stage data by time interval demonstrated that patients diagnosed with distant disease constituted 5\% of all OT carcinoma cases in 1973-1981 compared to $7 \%$ in $2000-2008$, whereas the proportion of unstaged disease decreased slightly between the two time intervals from 4 to $3 \%$. The corresponding comparison of data for BTT carcinomas demonstrated a decrease from 20 to $15 \%$ and from 8 to $3 \%$ for distant and unstaged disease, respectively.

\section{Discussion}

Improved survival observed among patients with advanced $\mathrm{BTT}$ tumors compared to OT tumors appears to be independent of ethnic origin. This improvement may be related to advancing therapy for patients with head and neck cancer, namely by introducing concurrent modality therapy in the 1990s, but it may also be related to 
Table 2. Observed and relative survival after diagnosis of SCC of tongue and tonsils by age, race, gender, site, stage and time interval (SEER data, 1973-2008)

\begin{tabular}{|c|c|c|c|c|c|c|c|}
\hline \multirow{3}{*}{$\begin{array}{l}\text { Case } \\
\text { characteristics }\end{array}$} & \multirow[t]{3}{*}{ Cases $^{\mathrm{a}}$} & \multicolumn{6}{|c|}{ Survival interval, \% } \\
\hline & & \multicolumn{2}{|l|}{1 year } & \multicolumn{2}{|l|}{3 years } & \multicolumn{2}{|l|}{5 years } \\
\hline & & observed & relative & observed & relative & observed & relative \\
\hline \multicolumn{8}{|l|}{ Age } \\
\hline$<40$ years & 1,825 & 88.80 & 89.00 & 71.30 & 71.60 & 67.50 & 68.10 \\
\hline $40-59$ years & 19,748 & 85.40 & 86.00 & 66.00 & 67.40 & 58.40 & 60.70 \\
\hline $60-79$ years & 17,923 & 76.40 & 78.40 & 51.90 & 56.40 & 42.10 & 48.80 \\
\hline $80+$ years & 2,752 & 60.10 & 66.70 & 34.10 & 47.70 & 22.80 & 41.50 \\
\hline \multicolumn{8}{|l|}{ Race } \\
\hline White & 35,757 & 81.30 & 83.00 & 60.20 & 63.90 & 51.40 & 57.10 \\
\hline Black & 4,161 & 67.40 & 68.90 & 37.60 & 40.20 & 29.30 & 32.80 \\
\hline Other & 2,083 & 83.40 & 84.60 & 62.90 & 65.70 & 56.00 & 60.30 \\
\hline Unknown & 247 & 86.90 & 88.80 & 77.00 & 82.10 & 70.90 & $78.6^{\mathrm{b}}$ \\
\hline \multicolumn{8}{|l|}{ Gender } \\
\hline Male & 30,332 & 80.30 & 81.90 & 58.20 & 61.80 & 49.40 & 54.70 \\
\hline Female & 11,916 & 79.50 & 81.20 & 57.80 & 61.50 & 49.60 & 55.10 \\
\hline \multicolumn{8}{|l|}{ Site } \\
\hline OT & 9,642 & 84.10 & 86.10 & 61.30 & 65.90 & 53.10 & 60.20 \\
\hline BTT & 27,618 & 79.70 & 81.10 & 58.10 & 61.30 & 49.00 & 53.70 \\
\hline Tongue, NOS & 4,988 & 74.20 & 76.10 & 52.00 & 56.00 & 44.70 & 50.90 \\
\hline \multicolumn{8}{|l|}{ Stage } \\
\hline Localized & 11,777 & 91.30 & 93.50 & 73.00 & 78.50 & 63.20 & 71.70 \\
\hline Regional & 22,831 & 79.90 & 81.40 & 57.30 & 60.30 & 48.80 & 53.40 \\
\hline Distant & 5,649 & 59.60 & 60.70 & 33.10 & 35.00 & 25.80 & 28.40 \\
\hline Unstaged & 1,991 & 72.50 & 74.50 & 48.30 & 51.90 & 39.20 & 44.30 \\
\hline \multicolumn{8}{|l|}{ Time interval } \\
\hline 1973-1981 & 4,773 & 71.80 & 73.70 & 43.60 & 47.10 & 34.50 & 39.40 \\
\hline 1982-1991 & 6,133 & 75.80 & 77.70 & 49.40 & 53.10 & 40.10 & 45.50 \\
\hline $1992^{c}-1999$ & 7,827 & 79.40 & 81.10 & 56.80 & 60.60 & 48.10 & 53.60 \\
\hline $2000^{\mathrm{c}}-2008$ & 23,515 & 83.30 & 84.80 & 65.00 & 68.40 & 57.50 & 62.90 \\
\hline All cases & 42,248 & 80.10 & 81.70 & 58.10 & 61.70 & 49.50 & 54.90 \\
\hline
\end{tabular}

NOS $=$ Not otherwise specified.

${ }^{a}$ Excludes cases that represent second or later primary cancer $(n=8,469)$, cases ascertained from autopsy records or death certificates $(\mathrm{n}=34)$, as well as cases known to be alive but without documented follow-up time $(\mathrm{n}=341){ }^{\mathrm{b}}$ The relative cumulative rate increased from a prior interval and has been adjusted. ${ }^{c}$ Years when new registries were added to the SEER program.

the increase in HPV-driven BTT tumors. Of note is the steep decline in survival curves for AAs, particularly for those with advanced disease, suggesting other factors involved, possibly related to increased treatment complications, lack of access to adequate follow-up, or a rapid disease progression.

For early-stage disease, patients with OT cancer appear to have a better survival compared to those with BTT carcinomas regardless of ethnic origin, even though the difference appears to be more pronounced in the white population. A possible explanation is the earlier detection of oral cavity lesions compared to oropharyngeal tumors, but other biologic factors may also be involved. It is of interest that oral cancer is decreasing in all groups except in white females which begs an additional analysis in this particular group as far as contributing environmental or other factors. Possible causes, next to other currently unknown environmental factors, may include the increased recent trend in smoking among women, or the rising incidence of the HPV-associated base of tongue 
Table 3. Multivariate Cox regression analyses evaluating the association between patient characteristics and survival following diagnosis of cancer of tongue and tonsils (SEER data, 17 registries, 1973-2008)

\begin{tabular}{|c|c|c|c|c|}
\hline \multirow{2}{*}{$\begin{array}{l}\text { Case } \\
\text { characteristics }\end{array}$} & \multicolumn{2}{|c|}{ Localized disease } & \multicolumn{2}{|c|}{ Advanced disease } \\
\hline & HR & $95 \% \mathrm{CI}$ & HR & $95 \% \mathrm{CI}$ \\
\hline \multicolumn{5}{|l|}{ Age group } \\
\hline$<40$ years & 1.00 & ref. & 1.0 & ref. \\
\hline 40-59 years & 2.29 & $1.92-2.73$ & 1.43 & $1.28-1.59$ \\
\hline $60-79$ years & 4.37 & $3.67-5.19$ & 2.42 & $2.18-2.70$ \\
\hline $80+$ years & 9.67 & $8.02-11.67$ & 4.84 & $4.28-5.47$ \\
\hline \multicolumn{5}{|l|}{$\operatorname{Race}^{\mathrm{a}}$} \\
\hline Whites & 1.00 & ref. & & ref. \\
\hline Blacks & 1.59 & $1.43-1.77$ & 1.92 & $1.83-2.00$ \\
\hline Other & 0.78 & $0.68-0.88$ & 0.89 & $0.81-0.96$ \\
\hline \multicolumn{5}{|l|}{ Gender } \\
\hline Female & 1.00 & ref. & 1.0 & ref. \\
\hline Male & 1.20 & $1.13-1.27$ & 1.04 & $1.00-1.08$ \\
\hline \multicolumn{5}{|l|}{ Site } \\
\hline OT & 1.00 & ref. & 1.0 & ref. \\
\hline BTT & 1.28 & $1.21-1.36$ & 0.72 & $0.69-0.75$ \\
\hline \multicolumn{5}{|l|}{ Time interval } \\
\hline 1973-1981 & 1.00 & ref. & 1.00 & ref. \\
\hline $1982-1991$ & 0.88 & $0.81-0.95$ & 0.84 & $0.80-0.89$ \\
\hline $1992^{b}-1999$ & 0.74 & $0.68-0.81$ & 0.66 & $0.63-0.69$ \\
\hline $2000^{\mathrm{b}}-2008$ & 0.59 & $0.54-0.65$ & 0.51 & $0.48-0.53$ \\
\hline
\end{tabular}

Analyses include all variables in the table, plus SEER registry. ref. $=$ Reference .

${ }^{\text {a }}$ Excludes patients with unknown race.

${ }^{b}$ Years when new registries were added to the SEER program.

carcinoma being misclassified as OT disease. HPV subtypes besides types 16 and 18 may also be playing a role in OT tumors. Other possibilities may include other tumorigenic viral infections or environmental exposures to carcinogens. Examining the biology of oral cavity tumors in women as well as population trends with adequate risk data collection such as smoking and alcohol use as well as sexual practices may shed some light on the etiologies behind these observed trends.

It is well reported that AAs experience higher incidence and mortality rates for other cancer types [11]. In a survival analysis from a retrospective study of a multicenter randomized phase III trial, there was a clear disparity in survival between AAs and Whites (20.9 vs. 70.6 months) attributable predominantly to BTT tumors (25.2 vs. 69.4 months in AAs and Whites, respectively), which is in keeping with the observed HPV trends [12]. Our findings indicate a similar discrepancy in OT tumors, a predominantly non-HPV-driven type of SCC, arguing against HPV as the sole driving factor behind ethnic origin disparities. These differences were also observed in the 80 s and early 90 s, prior to the noted increase in HPVdriven BTT carcinomas [11], and thus, argue against HPV as the predominant reason for these ethnic origin outcome disparities and point towards factors such as access to healthcare and early diagnosis as possible causes. It remains unclear as to why BTT carcinomas are decreasing in females which seems to be independent of ethnic origin.

The large sample size enables SEER-based studies to have sufficient power of detecting relatively moderate associations and permits a variety of stratified and multivariate analyses [21, 22]. Population-based, as opposed to institution-based, studies increase the external validity and generalizability of findings. Limitations of our study include the lack of information on the extent of surgery, type of chemo- and/or radiation therapy and the HPV status of patients, all of which may have impacted our results. Other limitations include the possible lack of uniformity in determinations of the site of malignancy, differences in disease staging methodologies over time, as well as evolving treatment options which have changed significantly in the early 90 s by the adoption of concurrent modality therapy in treating locally advanced disease. One other limitation is the multiple changes over time of how the SEER data code the stage of the disease. Recognizing this limitation, we have reclassified all cases using a 'historic staging' scheme that stratifies patients' stages into localized, regional and distant. With this approach we probably lost some of the staging detail, but preserved the consistency of data over a period of 3 decades. Additional limitations include the inadequate assessment of risk and prognostic factors such as tobacco and/or alcohol use as well as the lack of information related to type of therapy in addition to HPV status. Overall, our findings, we believe, raise multiple questions that need to be addressed through additional populationbased studies examining possible environmental or behavioral factors to better explain the observed trends.

\section{Conclusions}

The differences in sex- and ethnic origin-specific incidence of BTT cancers can be explained by the surge in HPV-related BTT tumors among white men; however, the driving factors behind the increasing rate of $\mathrm{OT}$ in 
white women as well as the sudden decreased incidence of BTT in black men remain unclear. Are these trends related to changes in rates of alcohol or tobacco use in the respective groups or are other factors involved? As ethnic origin remains a prognostic factor regardless of stage and primary site of disease this begs further study of the reasons behind these disparities. Additional populationbased studies are needed to explain the noted differences in incidence and survival across different subgroups of the population.

\section{Acknowledgment}

This work was supported in part by a PHS grant (UL1 RR025008) from the Clinical and Translational Science Award Program, National Institutes of Health, National Center for Research Resources.

\section{References}

1 Parkin DM, Pisani P, Ferlay J: Statistics are given for global patterns of cancer incidence and mortality for males and females in 23 regions of the world. CA Cancer J Clin 1999;49: 33-64.

-2 Jemal A, Siegel R, Ward E, Hao Y, Xu J, Thun MJ: Cancer statistics, 2009. CA Cancer J Clin 2009:59:225-249.

-3 Gillison ML, Koch WM, Capone RB, et al: Evidence for a causal association between human papillomavirus and a subset of head and neck cancers. J Natl Cancer Inst 2000;92: 709-720.

-4 Ang KK, Harris J, Wheeler R, et al: Human papillomavirus and survival of patients with oropharyngeal cancer. N Engl J Med 2010; 363:24-35.

5 Gillison ML: Human papillomavirus-associated head and neck cancer is a distinct epidemiologic, clinical, and molecular entity. Semin Oncol 2004;31:744-754.

-6 Parkin DM, Bray F, Ferlay J, Pisani P: Global cancer statistics, 2002. CA Cancer J Clin 2005;55:74-108.

7 Warnakulasuriya S: Global epidemiology of oral and oropharyngeal cancer. Oral Oncol 2008;45:309-316.

-8 D'Souza G, Kreimer AR, Viscidi R, et al: Case-control study of human papillomavirus and oropharyngeal cancer. N Engl J Med 2007;356:1944-1956.
-9 Fakhry C, Westra WH, Li S, et al: Improved survival of patients with human papillomavirus-positive head and neck squamous cell carcinoma in a prospective clinical trial. J Natl Cancer Inst 2008;100:261-269.

10 Gillison ML, Harris J, Westra W, et al: Survival outcomes by tumor human papillomavirus (HPV) status in stage III-IV oropharyngeal cancer (OPC) in RTOG 0129. J Clin Oncol 2009;27:6003.

11 Walker B, Figgs LW, Zahm SH: Differences in cancer incidence, mortality, and survival between African Americans and Whites. Environ Health Perspect 1995;103(suppl 8):275-281.

12 Settle K, Posner MR, Schumaker LM, et al: Racial survival disparity in head and neck cancer results from low prevalence of human papillomavirus infection in black oropharyngeal cancer patients. Cancer Prev Res (Phila) 2009;2:776-781.

13 Hankey BF, Ries LA, Edwards BK: The Surveillance, Epidemiology and End Results Program: a national resource. Cancer Epidemiol Biomarkers Prev 1999;8:1117-1121.

14 Fritz A, Percy C, Jack A, Sobin L, Parkin DM, Whelan S: International Classification of Diseases for Oncology, ed 3. Geneva, World Health Organization, 2000

15 Surveillance, Epidemiology and End Results (SEER) Program (www.seer.cancer.gov) SEER*Stat Database: Incidence - SEER 17 Regs Research Data + Hurricane Katrina Impacted Louisiana Cases. Linked to County Attributes - Total US, 1969-2007 Counties, National Cancer Institute, DCCPS, Surveillance Research Program, Cancer Statistics Branch, released April 2010, based on the November 2009 submission.
16 National Cancer Institute: SEER as a research resource. NIH Publication No 107519. Bethesda, February 2010. http://wwwseercancergov/about/SEER_research_brochurepdf.

17 Surveillance, Epidemiology and End Results Program GoST. http://wwwseercancergov/ cgi-bin/glossary/glossarypl\#glossary-27 2011.

18 Kim HJ, Fay MP, Feuer EJ, Midthune DN: Permutation tests for joinpoint regression with applications to cancer rates. Stat Med 2000;19:335-351

19 Kleinbaum D: Survival Analysis: A SelfLearning Text. New York, Springer, 1995.

20 Blomberg M, Nielsen A, Munk C, Kjaer SK: Trends in head and neck cancer incidence in Denmark, 1978-2007: focus on human papillomavirus associated sites. Int J Cancer 2011;129:733-741.

-21 Ludwig MS, Goodman M, Miller DL, Johnstone PA: Postoperative survival and the number of lymph nodes sampled during resection of node-negative non-small cell lung cancer. Chest 2005;128:1545-1550.

22 Esiashvili N, Goodman M, Marcus RB Jr: Changes in incidence and survival of Ewing sarcoma patients over the past 3 decades: Surveillance, Epidemiology and End Results data. J Pediatr Hematol Oncol 2008;30:425430 